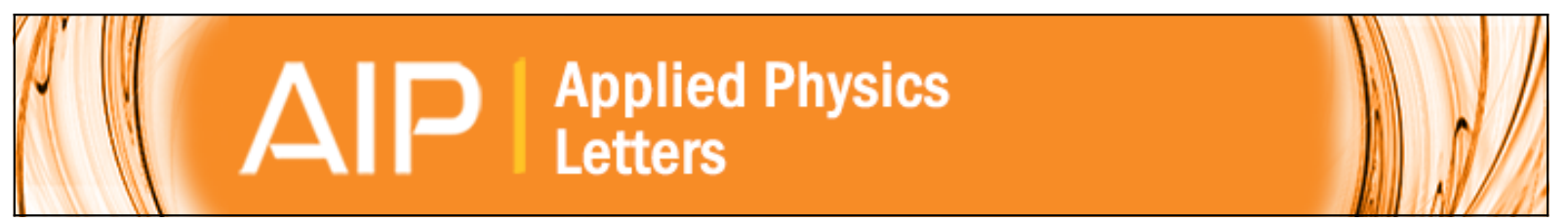

\title{
Dramatic enhancement of fullerene anion formation in polymer solar cells by thermal annealing: Direct observation by electron spin resonance
}

Dong Liu, Tatsuya Nagamori, Masaki Yabusaki, Takeshi Yasuda, Liyuan Han, and Kazuhiro Marumoto

Citation: Applied Physics Letters 104, 243903 (2014); doi: 10.1063/1.4883858

View online: http://dx.doi.org/10.1063/1.4883858

View Table of Contents: http://scitation.aip.org/content/aip/journal/apl/104/24?ver=pdfcov

Published by the AIP Publishing

\section{Articles you may be interested in}

High efficiency hybrid solid state blended dyes sensitized solar cell based on zinc oxide nanostructures

J. Renewable Sustainable Energy 5, 033134 (2013); 10.1063/1.4811818

Direct and charge transfer state mediated photogeneration in polymer-fullerene bulk heterojunction solar cells Appl. Phys. Lett. 100, 193302 (2012); 10.1063/1.4711849

Surface segregation at the aluminum interface of poly(3-hexylthiophene)/fullerene solar cells

Appl. Phys. Lett. 96, 043305 (2010); 10.1063/1.3294290

Origin of the efficiency improvement in all-polymer solar cells upon annealing

Appl. Phys. Lett. 91, 073518 (2007); 10.1063/1.2772185

Correlation between oxidation potential and open-circuit voltage of composite solar cells based on blends of polythiophenes/ fullerene derivative

Appl. Phys. Lett. 84, 1609 (2004); 10.1063/1.1650878

\section{A|P| $\begin{aligned} & \text { Journal of } \\ & \text { Applied Physics }\end{aligned}$}

Journal of Applied Physics is pleased to announce André Anders as its new Editor-in-Chief 


\title{
Dramatic enhancement of fullerene anion formation in polymer solar cells by thermal annealing: Direct observation by electron spin resonance
}

\author{
Dong Liu, ${ }^{1}$ Tatsuya Nagamori, ${ }^{1}$ Masaki Yabusaki, ${ }^{1}$ Takeshi Yasuda, ${ }^{2}$ Liyuan Han, ${ }^{2}$ \\ and Kazuhiro Marumoto ${ }^{1,3,4, a)}$ \\ ${ }^{1}$ Division of Materials Science, University of Tsukuba, Tsukuba, Ibaraki 305-8573, Japan \\ ${ }^{2}$ National Institute for Materials Science, Tsukuba, Ibaraki 305-0047, Japan \\ ${ }^{3}$ Japan Science and Technology Agency (JST), PRESTO, Kawaguchi, Saitama 322-0012, Japan \\ ${ }^{4}$ Tsukuba Research Center for Interdisciplinary Materials Science (TIMS), University of Tsukuba, Tsukuba, \\ Ibaraki 305-8571, Japan
}

(Received 28 January 2014; accepted 2 June 2014; published online 17 June 2014)

\begin{abstract}
Using electron spin resonance (ESR), we clarified the origin of the efficiency degradation of polymer solar cells containing a lithium-fluoride $(\mathrm{LiF})$ buffer layer created by a thermal annealing process after the deposition of an $\mathrm{Al}$ electrode (post-annealing). The device structure was indium-tin-oxide/ poly(3,4-ethylenedioxythiophene):poly(4-styrenesulfonate)/poly(3-hexylthiophene):phenyl- $\mathrm{C}_{61}$-butyric acid methyl ester (P3HT:PCBM)/LiF/Al. Three samples consisting of quartz/P3HT:PCBM/LiF/Al, quartz/P3HT:PCBM/Al, and quartz/PCBM/LiF/Al were investigated and compared. A clear ESR signal from radical anions on the PCBM was observed after LiF/Al was deposited onto a P3HT:PCBM layer because of charge transfer at the interface between the PCBM and the $\mathrm{LiF} / \mathrm{Al}$, which indicated the formation of $\mathrm{PCBM}^{-} \mathrm{Li}^{+}$complexes. The number of radical anions on the PCBM was enhanced remarkably by the post-annealing process; this enhancement was caused by the surface segregation of PCBM and by the dissociation of $\mathrm{LiF}$ at the $\mathrm{Al}$ interface by the post-annealing process. The formation of a greater number of anions enhanced the electron scattering, decreased the electron-transport properties of the PCBM molecules, and caused an energy-level shift at the interface. These effects led to degradation in the device performance. (c) 2014 AIP Publishing LLC. [http://dx.doi.org/10.1063/1.4883858]
\end{abstract}

Organic thin-film solar cells have attracted tremendous interest as a future technology for renewable energy because of their printable and flexible device structure, light weight, and low-cost production. ${ }^{1-3}$ One of the most widely studied organic thin-film solar cells employs an active layer of blend films with poly(3-hexylthiophene) (P3HT) and phenyl$\mathrm{C}_{61}$-butyric acid methyl ester (PCBM). The power-conversion efficiency (PCE) of the solar cells has been improved up to $3 \%-5 \%$ using a variety of methods, such as the insertion of a LiF buffer layer, ${ }^{4-6}$ thermal annealing, ${ }^{7-11}$ solvent annealing, ${ }^{12,13}$ and the use of mixed solvents. ${ }^{14}$ In particular, the effects of LiF insertion and thermal annealing have drastically improved the PCE, as explained below.

The interfaces between the metal electrodes and the organic semiconductors become critically important for improving the performance of the cells. To alter the interface properties, a LiF buffer layer between the electrodes and organic semiconductors is most commonly used. ${ }^{15}$ The most important effect of $\mathrm{LiF}$ is related to its function as a dipole layer. ${ }^{4,5}$ The LiF layer imparts a significant vacuum-level offset, which results in a reduction in the interfacial energy barriers. ${ }^{4,5} \mathrm{LiF}$ is also utilized to block holes and diminish electron-hole recombination near $\mathrm{Al}$ electrodes. ${ }^{6}$

To achieve high efficiency in devices, thermal annealing is often used to control the morphology of the blend films. ${ }^{7-11}$ Thermal annealing typically consists of two stages: pre-annealing, which is used on films prior to the deposition of metal electrodes, and post-annealing, which is used for

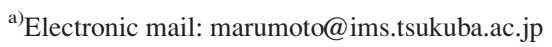

fabricated devices after the deposition of metal electrodes. ${ }^{16}$ Pre-annealing has been reported to improve the efficiency of solar cells containing $\mathrm{LiF}^{16}{ }^{16}$ whereas post-annealing has been reported to improve the efficiency of solar cells that do not contain $\mathrm{LiF}^{7-9,11}$ However, detailed studies of the effects of annealing on device performance using microscopic characterization have not yet been published.

Electron spin resonance (ESR) is a promising method for microscopic characterization because it is highly sensitive and can be utilized to investigate organic materials and devices at the molecular level. ${ }^{17-20}$ ESR can be used to investigate the correlation between microscopic ESR parameters and the macroscopic deterioration of the performance of solar cells. ${ }^{20} \mathrm{Li}$ et al. have reported that the LiF buffer layer is modified by the post-annealing. ${ }^{16}$ However, no ESR study investigating device after thermal annealing has been reported. Such a study would be useful for microscopically clarifying the phenomena by which the LiF buffer layer changes morphology, as well as how the change in blend films occurs during thermal annealing.

In this investigation, we studied the effects of thermal annealing on the LiF buffer layer using ESR. We compared the ESR results with the device characteristics. For solar cells containing LiF, the ESR signal resulting from the radical anions on the PCBM could be clearly observed without annealing. In contrast, no ESR signal from the PCBM was observed for solar cells that did not contain LiF. The observed ESR signals are due to charge transfer at the interface between the PCBM and $\mathrm{LiF} / \mathrm{Al}$, which indicates the formation of $\mathrm{PCBM}^{-} \mathrm{Li}^{+}$complexes. Surprisingly, the number 
of radical anions on the PCBM is remarkably enhanced and the PCE is considerably decreased by the post-annealing process. These phenomena can be explained in terms of morphological changes in the P3HT:PCBM/LiF/Al films during post-annealing. The radical anions formed on the PCBM inhibit electron transport in the PCBM molecules, ${ }^{21}$ which degrades device performance.

The structure of the polymer solar cells we studied was as follows: indium-tin-oxide (ITO)/poly(3,4-ethylenedioxythiophene):poly(4-styrenesulfonate) (PEDOT:PSS) $(\approx 40 \mathrm{~nm}) / \mathrm{P} 3 \mathrm{HT}: \mathrm{PCBM}(\approx 120 \mathrm{~nm}) / \mathrm{LiF}(\approx 1 \mathrm{~nm}$ or none $) / \mathrm{Al}$ $(80 \mathrm{~nm})$. We fabricated solar cells with active areas of $2 \mathrm{~mm} \times 2 \mathrm{~mm}$ on a $20 \mathrm{~mm} \times 20 \mathrm{~mm}$ glass substrate for the current density $(J)$-voltage $(V)$ characteristics and of $2 \mathrm{~mm} \times 10 \mathrm{~mm}$ on a $3 \mathrm{~mm} \times 20 \mathrm{~mm}$ quartz substrate for the ESR measurements. ${ }^{19,20}$ We also fabricated organic thin-film samples of quartz/P3HT:PCBM or PCBM/LiF ( $1 \mathrm{~nm}$ or none)/Al on a $3 \mathrm{~mm} \times 20 \mathrm{~mm}$ quartz substrate for the ESR measurements. The samples without ITO/PEDOT:PSS were studied for the following reasons. First, the primary purpose of this study was to use ESR to determine the effects of thermal annealing on the LiF buffer layer. Because ESR can be used to directly observe spins in materials, the most effective method of unambiguously investigating these effects was to use ESR to study quartz/organic layer/LiF/Al samples. Second, the ESR signals from PEDOT:PSS and P3HT overlap with each other, ${ }^{19,20}$ hindering the clear identification of the P3HT signal. To avoid this overlap, we primarily present ESR data for samples without ITO/PEDOT:PSS in this study.

Solutions of P3HT and PCBM (1:1 w/w) were dissolved in $o$-dichlorobenzene $(3.0 \mathrm{wt} . \%)$ and stirred for $15 \mathrm{~h}$ at $40^{\circ} \mathrm{C}$. They were then spin-coated onto the PEDOT:PSS films. We defined pre-annealing as the annealing of the fabricated layer at $110^{\circ} \mathrm{C}$ for $10 \mathrm{~min}$ before the electrode was deposited. $\mathrm{LiF} / \mathrm{Al}$ or $\mathrm{Al}$ layers were deposited onto the P3HT:PCBM layer to form the cathode using a vacuumsublimation technique at pressures less than $1 \times 10^{-4} \mathrm{~Pa}$. We defined post-annealing as the annealing of the fabricated device at $110^{\circ} \mathrm{C}$ for $10 \mathrm{~min}$ after the electrode was deposited. All thermal annealing treatments were performed in a nitrogen-filled glove box $\left(<0.2 \mathrm{ppm} \mathrm{O}_{2},<0.6 \mathrm{ppm} \mathrm{H}_{2} \mathrm{O}\right)$. The ESR measurements were performed in the dark at room temperature under a $\mathrm{N}_{2}$ atmosphere using a JEOL JES-FA200 X-band spectrometer. The number of spins and the $g$ factor of the ESR signal were calibrated using a standard $\mathrm{Mn}^{2+}$ marker sample.

First, we present the $J-V$ characteristics. Figures 1(a) and 1 (b) show the data for solar cells without and with $\mathrm{LiF}$ that were fabricated using different thermal annealing conditions. The device performance is summarized in Table I. The performance of the solar cell without $\mathrm{LiF}$ was improved by thermal annealing, which can be explained by the improved crystallinity of the P3HT for the "Al pre-annealed" device 7,8 and by the surface segregation of the PCBM at the Al electrode for the "Al post-annealed" device. ${ }^{11}$ In clear contrast to the results obtained for solar cells without $\mathrm{LiF}$, the "LiF/Al unannealed" device exhibited the best performance, with a PCE of $3.58 \%$. The PCE decreased to $2.75 \%$ for the "LiF/Al post-annealed" device. Therefore, post-annealing of devices
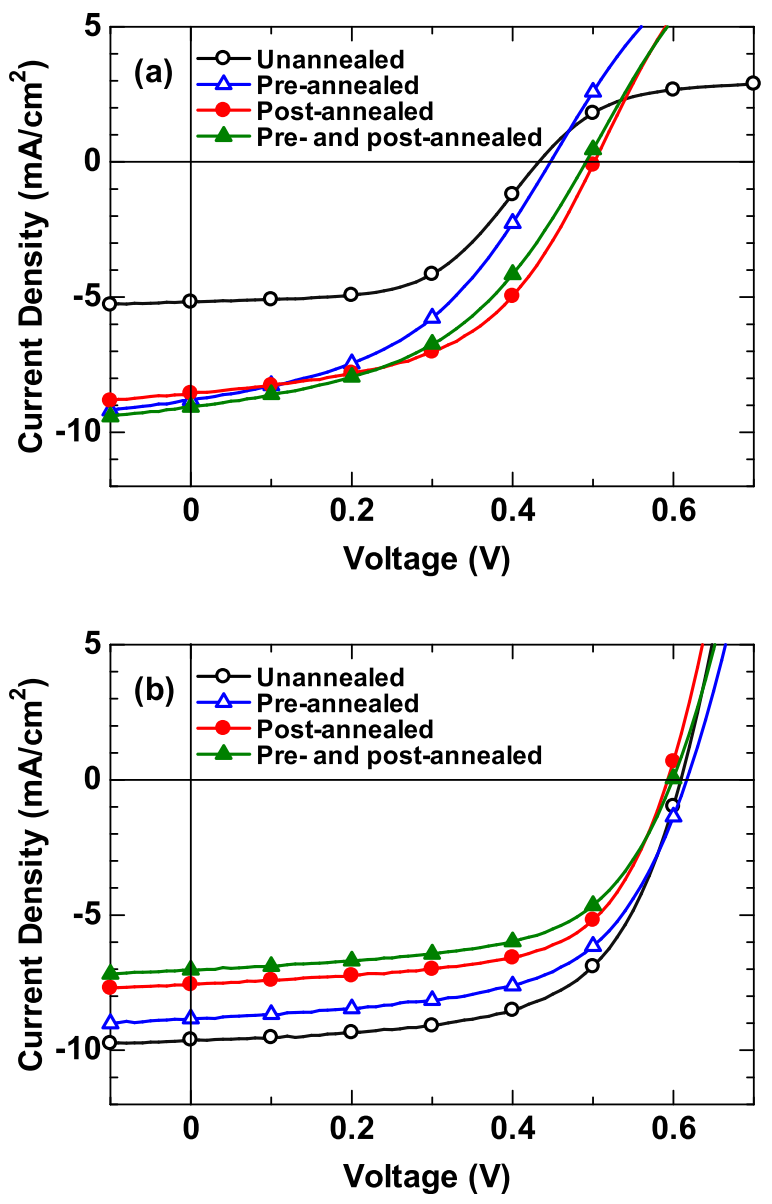

FIG. 1. $J$ - $V$ characteristics of (a) ITO/PEDOT:PSS/P3HT:PCBM/Al and (b) ITO/PEDOT:PSS/P3HT:PCBM/LiF/Al subjected to various thermal annealing treatments; the samples were exposed to simulated solar irradiation at room temperature.

with LiF negatively affects the photovoltaic properties of the devices. ${ }^{16}$ No change in the spectral shape of the incident photon-to-current conversion efficiency (IPCE) was observed after thermal annealing, which means the molecules did not degrade.

Next, we present the ESR results for two types of thinfilm samples to investigate the reaction between $\mathrm{LiF}$ and the organic molecules. Figures 2(a)-2(f) show the ESR signals for quartz/P3HT:PCBM/Al and quartz/P3HT:PCBM/LiF/Al annealed under different conditions. The vertical axis is plotted using units of peak-to-peak ESR intensity of the ESR

TABLE I. Performance of polymer solar cells fabricated with and without $\mathrm{LiF}$ buffer layers and subjected to various thermal annealing treatments at $110^{\circ} \mathrm{C}$.

\begin{tabular}{|c|c|c|c|c|c|}
\hline Electrodes & Annealing treatments & $\begin{array}{c}J_{\mathrm{sc}} \\
\left(\mathrm{mA} / \mathrm{cm}^{2}\right)\end{array}$ & $\begin{array}{l}V_{\mathrm{oc}} \\
(\mathrm{mV})\end{array}$ & FF & $\begin{array}{l}\text { PCE } \\
(\%)\end{array}$ \\
\hline $\mathrm{Al}$ & Unannealed & 5.17 & 430 & 0.56 & 1.25 \\
\hline $\mathrm{Al}$ & Pre-annealed & 8.81 & 450 & 0.44 & 1.74 \\
\hline $\mathrm{Al}$ & Post-annealed & 8.55 & 500 & 0.51 & 2.19 \\
\hline $\mathrm{Al}$ & Pre- and post-annealed & 9.07 & 490 & 0.46 & 2.04 \\
\hline $\mathrm{LiF} / \mathrm{Al}$ & Unannealed & 9.61 & 610 & 0.61 & 3.58 \\
\hline $\mathrm{LiF} / \mathrm{Al}$ & Pre-annealed & 8.83 & 610 & 0.59 & 3.19 \\
\hline $\mathrm{LiF} / \mathrm{Al}$ & Post-annealed & 7.56 & 590 & 0.61 & 2.75 \\
\hline $\mathrm{LiF} / \mathrm{Al}$ & Pre- and post-annealed & 7.03 & 590 & 0.59 & 2.48 \\
\hline
\end{tabular}


signal of a standard $\mathrm{Mn}^{2+}$ mark sample, $I_{\mathrm{Mn}}$. First, we discuss the results for quartz/P3HT:PCBM/Al. As shown in Figs. 2(a)-2(c), we observed only an ESR signal due to $\mathrm{P} 3 \mathrm{HT}$. The $g$ factor was determined to be $2.002 \pm 0.0002$, which is consistent with that of radical cations (positive polarons) on P3HT in organic field-effect devices. ${ }^{22,23}$ The ESR signals of PCBM radical anions have been reported to have $g$-tensor values of 1.9982-2.00058. ${ }^{24,25}$ Notably, the ESR signal for radical anions on PCBM cannot usually be observed at room temperature because of the rapid spin relaxation of the fullerene electrons at room temperature. $^{20,22,26}$

In clear contrast to the results for quartz/P3HT: $\mathrm{PCBM} / \mathrm{Al}$, we observed ESR signals for both P3HT and PCBM for quartz/P3HT:PCBM/LiF/Al, as shown in Figs. 2(d)-2(f). The ESR signal at $g=2.002 \pm 0.0002$ corresponds to the P3HT radical cations, whereas the signal at $g=1.999 \pm 0.0002$ corresponds to the PCBM radical anions. $^{22-26}$ The observation of the PCBM signal can most likely be ascribed to the formation of $\mathrm{PCBM}^{-} \mathrm{Li}^{+}$ charge-transfer complexes. In a previous study, the interaction between $\mathrm{LiF}$ and $\mathrm{C}_{60}$ followed by the deposition of $\mathrm{Al}$ was reported to produce the $\mathrm{ESR}$ signal of $\mathrm{C}_{60}$ radical anions, which is strongly suggested to be due to $\mathrm{C}_{60}{ }^{-} \mathrm{Li}^{+}$ charge-transfer complexes. ${ }^{27}$ Surprisingly, in the case of the post-annealing, we observed a remarkable increase in the ESR intensity from PCBM radical anions (see Figs. 2(d) and 2(f)). This result indicates that the number of PCBM radical anions, $N_{\text {spin }}$, increases remarkably due to post-annealing. The $N_{\text {spin }}$ increased from $1.19 \times 10^{13}$ before the post-annealing to $1.15 \times 10^{14}$ after the post-annealing, showing a one order of magnitude larger value by the post-annealing. This type of direct observation of the increase in the PCBM signal has not yet been reported. Two mechanisms may be responsible for this remarkable increase. First, the post-annealing process may enhance the surface segregation of PCBM at the LiF/Al interface. ${ }^{11}$ The second mechanism may be related to the increase in thermal energy for the dissociation of LiF. These mechanisms will be discussed further below.

To investigate the mechanisms for the formation of PCBM radical anions by post-annealing, we performed an ESR study on the samples of quartz/P3HT:PCBM/LiF/Al and quartz/PCBM/LiF/Al for different post-annealing temperatures. The ESR signal for PCBM radical anions increased with increasing post-annealing temperature, as shown in Fig. 3. The insets of Figs. 3(a) and 3(b) show the dependence of the $N_{\text {spin }}$ on the post-annealing temperature. The post-annealing temperature strongly influenced the formation of PCBM radical anions. For comparison, we measured the $J-V$ characteristics for solar cells containing LiF for different post-annealing temperatures. The device performance is summarized in Table II. The post-annealing temperature also affected the degradation of the device performance. The PCE monotonically decreased as the post-annealing temperature increased; this behavior can be attributed to the increase in $N_{\text {spin }}$ at higher temperatures.

The rate of increase in $N_{\text {spin }}$ for the two thin-film samples differed with respect to their post-annealing temperatures. The rate of increase in $N_{\text {spin }}$ for quartz/PCBM/LiF/Al at annealing temperatures greater than $110^{\circ} \mathrm{C}$ is less pronounced compared with that for quartz/P3HT:PCBM/LiF/Al
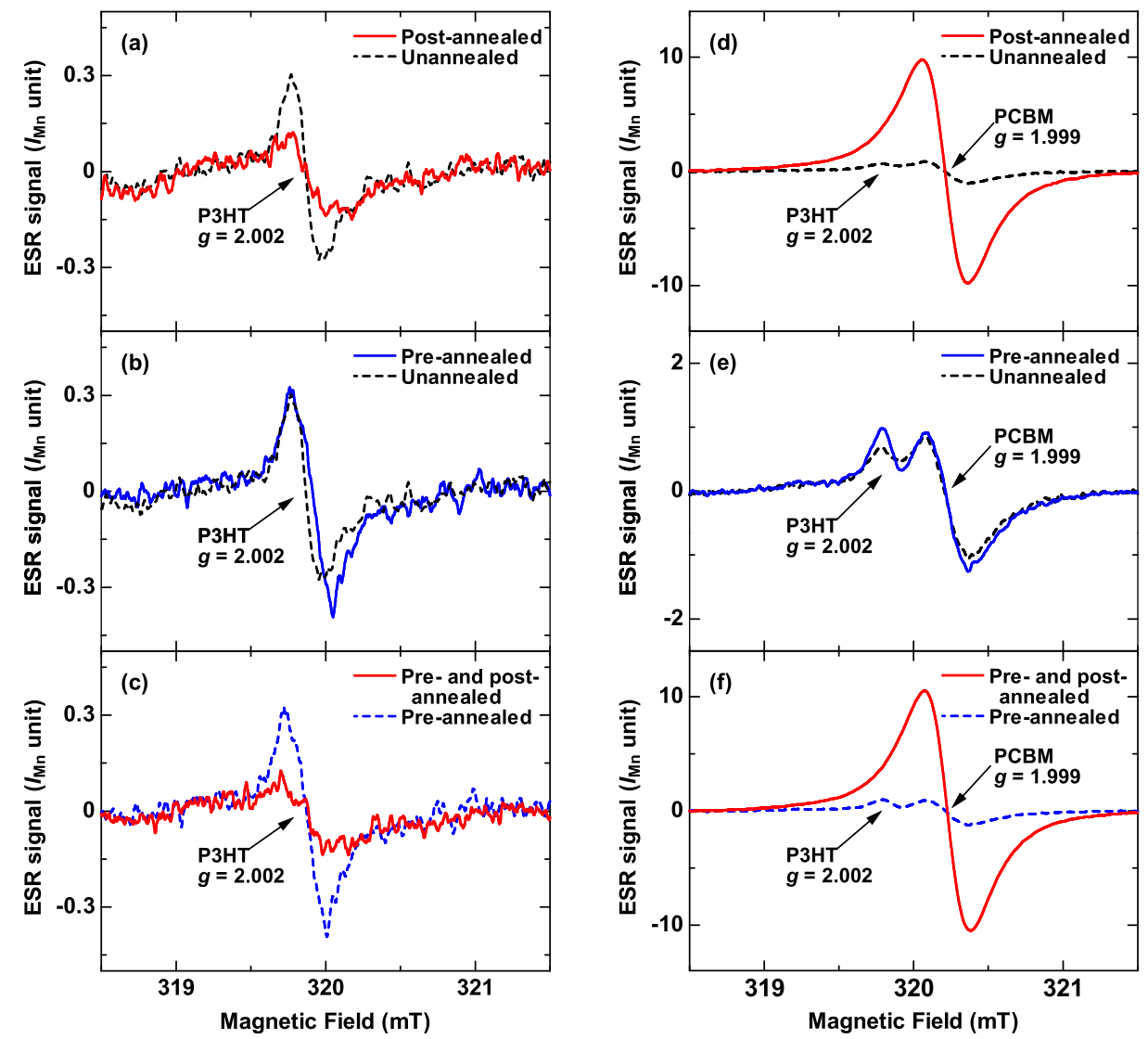

FIG. 2. The ESR signals of (a)-(c) quartz/P3HT:PCBM/Al and (d)-(f) quartz/P3HT:PCBM/LiF/Al subjected to various thermal annealing treatments. 

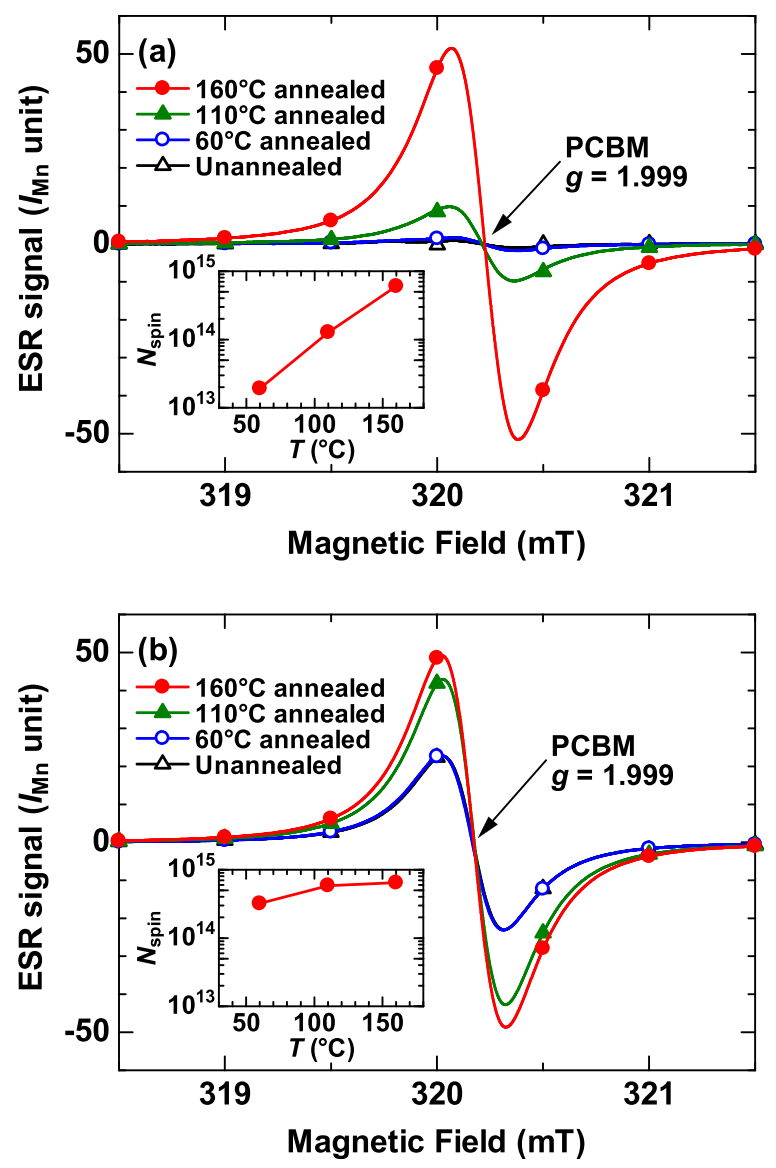

FIG. 3. ESR signals of (a) quartz/P3HT:PCBM/LiF/Al and (b) quartz/PCBM/LiF/Al post-annealed at various temperatures. Inset: dependence of the number of PCBM radical anions $\left(N_{\text {spin }}\right)$ on the annealing temperature.

(see Fig. 3(b)). This result indicates that the dissociation of $\mathrm{LiF}$ occurs even at low annealing temperatures. In contrast, the rate of increase in $N_{\text {spin }}$ for quartz/P3HT:PCBM/LiF/Al was considerably higher than that for quartz/PCBM/LiF/Al at annealing temperatures greater than $110^{\circ} \mathrm{C}$ (see Fig. 3(a)). This result indicates that the surface segregation of PCBM at the interface is further enhanced at higher annealing temperatures.

Next, we performed an ESR study of ITO/PEDOT:PSS/ P3HT:PCBM/LiF/Al to determine the relationship between the ESR signal and the device performance after the formation of PCBM radical anions. The ESR signal and the device performance were measured using the same device. The PCE decreased from $1.36 \%$ before thermal annealing to $0.67 \%$ after the post-annealing. We observed a tendency similar to that observed in Table I. Figure 4 presents the ESR

TABLE II. Performance of polymer solar cells fabricated with LiF buffer layers and subjected to various post-annealing temperatures.

\begin{tabular}{lccccc}
\hline \hline Electrodes & $\begin{array}{c}\text { Post-annealing } \\
\text { temperature }\end{array}$ & $\begin{array}{c}J_{\mathrm{sc}} \\
\left(\mathrm{mA} / \mathrm{cm}^{2}\right)\end{array}$ & $\begin{array}{c}V_{\mathrm{oc}} \\
(\mathrm{mV})\end{array}$ & $\mathrm{FF}$ & $\begin{array}{c}\text { PCE } \\
(\%)\end{array}$ \\
\hline $\mathrm{LiF} / \mathrm{Al}$ & Unannealed & 9.61 & 610 & 0.61 & 3.58 \\
$\mathrm{LiF} / \mathrm{Al}$ & $60^{\circ} \mathrm{C}$ & 8.47 & 610 & 0.61 & 3.14 \\
$\mathrm{LiF} / \mathrm{Al}$ & $110^{\circ} \mathrm{C}$ & 7.56 & 590 & 0.61 & 2.75 \\
$\mathrm{LiF} / \mathrm{Al}$ & $160^{\circ} \mathrm{C}$ & 8.65 & 540 & 0.53 & 2.46 \\
\hline \hline
\end{tabular}

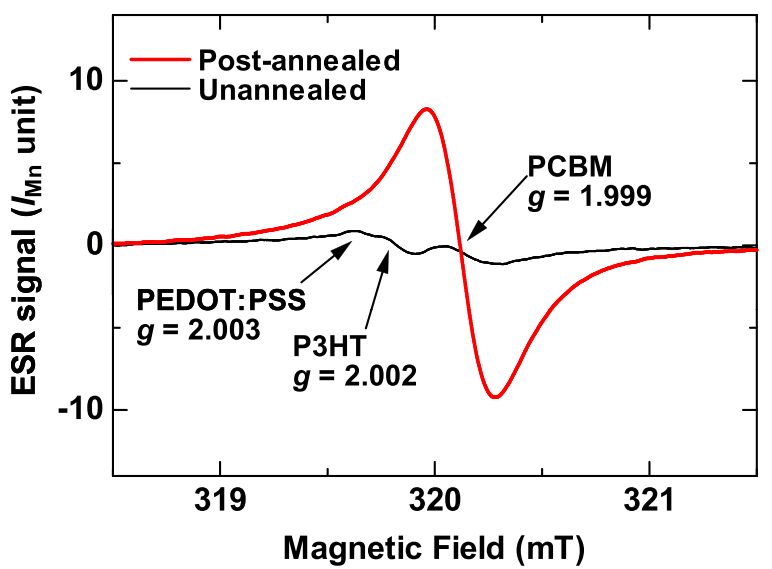

FIG. 4. ESR signals of ITO/PEDOT:PSS/P3HT:PCBM/LiF/Al with and without post-annealing treatment under open-circuit conditions.

signals for the device with and without post-annealing at $110^{\circ} \mathrm{C}$. ESR signals from the PEDOT:PSS $(g=2.003)$, the $\mathrm{P} 3 \mathrm{HT}$, and the PCBM were observed for the unannealed device. The ESR signal of the PEDOT:PSS and the P3HT overlapped with each other because of their similar $g$ factors. ${ }^{19,20}$ The intensity of the PCBM signal increased considerably after post-annealing. This dramatic enhancement was nearly identical to that observed for quartz/P3HT:PCBM/ LiF/Al (see Fig. 2(d)). Therefore, by investigating the same device with and without post-annealing, we confirmed the relationship between the increase in the ESR signal and the degradation of the device performance caused by the formation of radical anions on the PCBM during post-annealing. The stability of the PCBM radical anions was studied by applying a reverse bias of $-700 \mathrm{mV}$ to the device for $3 \mathrm{~h}$ after postannealing. No change in $N_{\text {spin }}$ was observed, which indicates that the PCBM radical anions are stable, most likely due to the formation of $\mathrm{PCBM}^{-} \mathrm{Li}^{+}$complexes rather than due to electron trappings in the PCBM.

We comment on the reason for the relatively low performance of the device. For the ESR measurements, we used cells with an active area of $2 \mathrm{~mm} \times 10 \mathrm{~mm}$. The film quality of such asymmetric and large areas deteriorated compared with that of the symmetric and small area of $2 \mathrm{~mm} \times 2 \mathrm{~mm}$ used for the $J-V$ characteristics, which resulted in diminished device performance. A device with such a large active area was used for the ESR measurements to overcome the low signal-to-noise (SN) ratio of the ESR signal; the SN ratio improves with increasing active area. ${ }^{20}$

Finally, we discuss the mechanism of the performance degradation. We examined the rate of the $\mathrm{LiF}$ dissociation. The $N_{\text {spin }}$ after post-annealing at $110^{\circ} \mathrm{C}$ was $1.15 \times 10^{14}$. On the basis of the volume of the $\operatorname{LiF}$ layer $\left(3 \times 10^{-8} \mathrm{~cm}^{3}\right)$, the number of $\mathrm{Li}$ atoms in the deposited $\mathrm{LiF}$ layer was $1.84 \times 10^{15}$. Thus, we found that only $6 \%$ of the $\mathrm{Li}$ atoms contributed to the formation of the PCBM radical anions during post-annealing. This result indicates that the thermal annealing process did not completely destroy the LiF function. For another mechanism, Harada et al. have reported that the mobility of $\mathrm{n}$-doped $\mathrm{C}_{60}$ decreases with increasing doping density because of the charge-carrier scattering by $\mathrm{C}_{60}$ anions. $^{21}$ On the basis of the similar characteristics of $\mathrm{C}_{60}$ and PCBM, the mobility can be reasonably inferred to 
decrease with increasing such carrier scattering. Anion formation decreases $J_{\mathrm{sc}}$ and concomitantly decreases $V_{\mathrm{oc}}{ }^{11}$ Anion formation should also decrease $V_{\mathrm{oc}}$ because of the shift in energy levels at the interfaces. ${ }^{19,20}$ The expected decrease in $V_{\text {oc }}$ was, indeed, observed (see Table II). In the following, we discuss the mechanism of the $J_{\text {sc }}$ decrease on the basis of carrier scattering from the formation of PCBM anions. Such scattering may be considered to be independent of other scattering mechanisms; thus, we can use Matthiessen's rule for the mobility $\mu^{21}$

$$
\frac{1}{\mu}=\frac{1}{\mu_{\mathrm{SC}}}+\frac{1}{\left(c / N_{\mathrm{spin}}\right) \mu_{\mathrm{AF}}} .
$$

Here, we use two mobility constituents, $\mu_{\mathrm{SC}}$ and $\mu_{\mathrm{AF}}$, which are related to the carrier scattering in the cells without and with the formation of PCBM anions, respectively. The latter depends on $N_{\text {spin }}$ with a proportionality constant $c$. Using Eq. (1), we can express the current density $j$ using the charge density $n$ and the internal electric filed $E$ in the cells as follows:

$$
j=n e \mu E=\frac{\mu_{\mathrm{SC}} \mu_{\mathrm{AF}}}{\mu_{\mathrm{AF}}+\left(\mu_{\mathrm{SC}} / c\right) N_{\mathrm{spin}}} E
$$

Equation (2) shows that $j$ decreases as $N_{\text {spin }}$ increases, which explains the experimental results. Therefore, carrier scattering induced by the formation of PCBM anions decreases $J_{\text {sc }}$.

In summary, we performed an ESR study of organic layered thin films and solar cells using P3HT:PCBM blend films subjected to different thermal annealing conditions. We investigated the degradation mechanism of cells containing a $\mathrm{LiF}$ buffer layer after post-annealing. We clearly observed an ESR signal from PCBM radical anions after the deposition of $\mathrm{LiF} / \mathrm{Al}$ onto P3HT:PCBM in dark conditions, which resulted from the formation of $\mathrm{PCBM}^{-} \mathrm{Li}^{+}$complexes at the PCBM/LiF interface. The number of PCBM anions was remarkably enhanced by the post-annealing, which is reasonably explained by the surface segregation of PCBM and the dissociation of $\mathrm{LiF}$ at the interface. The formation of PCBM anions caused the performance degradation. Thus, ESR is an extremely effective method for investigating the microscopic degradation mechanisms of organic solar cells because it can detect charge formation in devices during the various device fabrication steps.
This work was partly supported by a Grant-in-Aid for Scientific Research (No. 24560004) from the Japan Society for the Promotion of Science (JSPS) and by JST, PRESTO.

${ }^{1}$ Organic Photovoltaics: Concepts and Realization, edited by C. J. Brabec, V. Dyakonov, J. Parisi, and N. S. Sariciftci (Springer, Berlin, Germany, 2003), Vol. 60.

${ }^{2}$ S. Gunes, H. Neugebauer, and N. S. Sariciftci, Chem. Rev. 107, 1324 (2007).

${ }^{3}$ T. M. Clarke and J. R. Durrant, Chem. Rev. 110, 6736 (2010).

${ }^{4}$ C. J. Brabec, S. E. Shaheen, C. Winder, N. S. Sariciftci, and P. Denk, Appl. Phys. Lett. 80, 1288 (2002).

${ }^{5}$ E. Ahlswede, J. Hanisch, and M. Powalla, Appl. Phys. Lett. 90, 163504 (2007).

${ }^{6}$ B.-W. Yang, M.-Y. Tsai, W.-H. Chang, J.-S. Chen, S. L.-C. Hsu, and W.-Y. Chou, J. Phys. Chem. C 117, 14472 (2013).

${ }^{7}$ W. Ma, C. Yang, X. Gong, K. Lee, and A. J. Heeger, Adv. Funct. Mater. 15, 1617 (2005)

${ }^{8}$ T. Erb, U. Zhokhavets, G. Gobsch, S. Raleva, B. Stuhn, P. Schilinsky, C. Waldauf, and C. J. Brabec, Adv. Funct. Mater. 15, 1193 (2005).

${ }^{9}$ T. M. Clarke, A. M. Ballantyne, J. Nelson, D. D. C. Bradley, and J. R. Durrant, Adv. Funct. Mater. 18, 4029 (2008).

${ }^{10}$ Y. Kim, A. M. Ballantyne, J. Nelson, and D. D. C. Bradley, Org. Electron. 10, 205 (2009).

${ }^{11}$ A. Orimo, K. Masuda, S. Honda, H. Benten, S. Ito, H. Ohkita, and H. Tsuji, Appl. Phys. Lett. 96, 043305 (2010).

${ }^{12}$ S. Miller, G. Fanchini, Y.-Y. Lin, C. Li, C.-W. Chen, W.-F. Su, and M. Chhowalla, J. Mater. Chem. 18, 306 (2008).

${ }^{13}$ J. H. Park, J. S. Kim, J. H. Lee, W. H. Lee, and K. Cho, J. Phys. Chem. C 113, 17579 (2009).

${ }^{14}$ Y. Yao, J. H. Hou, Z. Xu, G. Li, and Y. Yang, Adv. Funct. Mater. 18, $1783(2008)$

${ }^{15}$ S. K. Jonsson, W. R. Salaneck, and M. Fahlman, J. Appl. Phys. 98, 014901 (2005).

${ }^{16}$ F. Li, J. Zhao, K. Yao, and Y. Chen, Chem. Phys. Lett. 553, 36 (2012).

${ }^{17}$ K. Marumoto, M. Kato, H. Kondo, S. Kuroda, N. C. Greenham, R. H. Friend, Y. Shimoi, and S. Abe, Phys. Rev. B 79, 245204 (2009).

${ }^{18}$ M. Tsuji, Y. Takahashi, Y. Sakurai, Y. Yomogida, T. Takenobu, Y. Iwasa, and K. Marumoto, Appl. Phys. Lett. 102, 133301 (2013).

${ }^{19}$ K. Marumoto, T. Fujimori, M. Ito, and T. Mori, Adv. Energy Mater. 2, 591 (2012).

${ }^{20}$ T. Nagamori and K. Marumoto, Adv. Mater. 25, 2362 (2013).

${ }^{21}$ K. Harada, F. Li, B. Maenning, M. Pfeiffer, and K. Leo, Appl. Phys. Lett. 91, 092118 (2007)

${ }^{22}$ K. Marumoto, T. Sakamoto, S. Watanabe, H. Ito, and S. Kuroda, Jpn. J. Appl. Phys., Part 2 46, L1191 (2007).

${ }^{23}$ S. Watanabe, H. Tanaka, S. Kuroda, A. Toda, S. Nagano, T. Seki, A. Kimoto, and J. Abe, Appl. Phys. Lett. 96, 173302 (2010).

${ }^{24}$ J. De Ceuster, E. Goovaerts, A. Bouwen, J. C. Hummelen, and V. Dyakonov, Phys. Rev. B 64, 195206 (2001).

${ }^{25}$ O. G. Poluektov, S. Filippone, N. Martín, A. Sperlich, C. Deibel, and V. Dyakonov, J. Phys. Chem. B 114, 14426 (2010).

${ }^{26}$ A. Aguirre, S. C. J. Meskers, R. A. J. Janssen, and H.-J. Egelhaaf, Org. Electron. 12, 1657 (2011)

${ }^{27}$ E. D. Glowacki, K. L. Marshall, C. W. Tang, and N. S. Sariciftci, Appl. Phys. Lett. 99, 043305 (2011) 